\title{
Effect of Antenatal Care (ANC) on Mental Well-Being Among Women Living in Low-Income Housing of Delhi, NCR
}

\author{
Aditi Puri ${ }^{1 *}$, Peter Nwakeze ${ }^{2}$, Mahmoud Ali Kaddoura ${ }^{3}$ and Christine Dominick ${ }^{4}$ \\ ${ }^{1}$ King Graduate School-Masters in Public Health, School of Allied Health, USA \\ ${ }^{2}$ King Graduate School, Monroe College, USA \\ ${ }^{3}$ University of San Francisco, USA \\ ${ }^{4}$ MCPHS University, USA
}

Submission: January 29, 2021; Published: February 09, 2021

*Corresponding author: Aditi Puri, King Graduate School-Masters in Public Health, School of Allied Health, USA

\begin{abstract}
Background: Marginalized women are at an increased risk of maternal mortality. Quality antenatal care (ANC) services can protect the health and well-being of mothers living in low-income housing.

Objective: To evaluate the effect of ANC quality on mental well-being among women living in low-income housing in Delhi.

Material: 155 pregnant women and new mothers were recruited from low-income housing in Delhi. Two measures were adapted to collect data for this cross-sectional study: 1. Quality of Prenatal Care Questionnaire 2. Warwick Edenberg Mental Well-Being Scale.

Results: Quality and time of ANC services were found to be significantly associated with mental well-being of women in both chi-square and logistic analysis. Women who accessed ANC in the 1st trimester were 4 times more likely to experience better mental well-being compared to women in the 3rd trimester (odds-ratio $=4.041, \mathrm{p}=.004$ ). Sixty-five percent of those who utilized ANC in 1st trimester reported high level of mental well-being (chi-square=16.095, p-value=.001). Those who accessed ANC in the 2 nd trimester were nearly 3 times more likely to report better mental well-being (odds-ratio $=2.570, \mathrm{p}=.049$ ). Women who accessed high quality of ANC were nearly 3 times more likely to experience better mental well-being (odds-ratio $=2.872$, $\mathrm{p}$-value $=.004$ ).
\end{abstract}

Conclusion: Quality ANC in the 1st trimester is critical for well-being of mothers. Governmental and non-governmental organizations should provide free access to quality ANC to protect the well-being of pregnant women and new mothers. Focused public health programs at state, district and national level can address inequities in maternal health among marginalized women in Delhi.

Keywords: Antenatal care; Mental Well-Being; Mother and Child Health; Quality; Low-Income Housing

\section{Introduction}

Access to quality healthcare services during the antenatal period and delivery is essential for the overall well-being of mother and child. Screening for health complications during the antenatal period is critical for reducing the health risks for mother and child. In addition, delivery at a well-equipped healthcare facility by a skilled-birth attendant (SBA) can significantly minimize complications during delivery [1] In India, the proportion of women 15-49 years old who seek antenatal care (ANC) has increased from $77 \%$ in National Family Health
Survey-3 (2005-2006) to 84\% in NFHS-4 (2015-2016). Fifty-nine percent of women first had ANC in the $1^{\text {st }}$ trimester, $18 \%$ in the $4 / 5^{\text {th }}$ month, and $7 \%$ in the $6^{\text {th }}$ month or later. Similarly, delivery at an institution has increased distinctly from $39 \%$ in 2005-2006 to $79 \%$ in $2015-2016$ [1]. Mother's education and income are highly correlated to institutional delivery. Ninety-five percent of women who had high-school education or above delivered at an institution compared to $66 \%$ with no schooling. Likewise, women in the highest income quintile (95\%) delivered at an institution compared to $60 \%$ of those in the lowest quintile [1]. 
In a study conducted in the urban slums of Delhi, $68.2 \%$ of women who delivered at an institution were attended by a doctor or a nurse. Those who delivered at home (62\%) were attended by a trained dai (traditional birth attendant). Mothers who utilized ANC preferred dais to a lesser extent (13.1\%) compared to those who did not use ANC services (66\%). Gupta et al. [2] in their study conducted in the slums of Jaipur, Mathura, Ludhiana, and Ujjain, noted that $51 \%$ of the women had antenatal check-ups at private hospitals while 30\% utilized governmental dispensaries and 8\% visited antenatal clinics. Sanneving et al. [3] in their review of the literature found gender, social and economic status to be closely interrelated to access and use of maternal and reproductive healthcare. The population which is systematically disadvantaged in terms of access to maternal and reproductive health services includes poor women, adolescents, Muslims, members of Scheduled Caste (SC) and Scheduled Tribe (ST) and poorly educated women [4]. Hazarika used data from NFHS-4 to compare utilization of reproductive health services among women living in slums and non-slums; $64.32 \%$ of women living in slums utilized ANC services in the $1^{\text {st }}$ trimester compared to $75.87 \%$ of the non-slum population. Twenty-three percent of the slum dwellers delivered at home compared to $15.5 \%$ of non-slum residents. Moreover, $79.61 \%$ of slum dwellers had SBA compared to $86.35 \%$ of non-slum residents [5]. Women's education and socio-economic status of the household are associated with utilization of ANC and SBA [6]. Women who belonged to the richest quintile were 4.53 times more likely to utilize ANC compared to women from the poorest quintile. Women with secondary or above education were 2.75 times more likely to use ANC compared to illiterate women [6]. Kumar et al. examined NFSH-4 data to assess equity in complete ANC utilization. Low income quintile, low mother's education, higher birth order, absence of father during antenatal visits and unintended pregnancy were associated with lower odds of full ANC utilization [7].

Quality of ANC in Migori County, Kenya was measured by receipt of recommended ANC services and experience of care. Women who were employed, literate and received all of their services from the health center had higher experience scores compared to those who were illiterate and unemployed. Moreover, the wealthiest women had two times higher odds of receiving an ultrasound compared to the poorest women [8]. Joshi et al. defined good quality ANC as that which includes all 7 recommended components: blood pressure, urine test, blood test for syphilis and anemia, provision of iron supplements, intestinal parasite drugs, Tetanus Toxide (TT) injections and health education. Receiving ANC from a skilled provider, receiving ANC in a hospital, urban residence, and exposure to general media were predictors of good quality ANC [9]. In a study conducted in the slums of Jaipur, Mathura, and Ludhiana, the quality of ANC was determined by two factors: health personnel availability at the time of visit; and if the facility was open during hours of operation, since this often depends on the availability of the doctor. Eighty-one percent of women noted that health professionals were available at the time of the visit; and almost all agreed that the facility was open during office hours [3].

Javed et al. [10] used a well-being scale to compare wellbeing among educated and uneducated Muslim housewives in Aligarh district. Although not significant, overall well-being among educated women was better than uneducated women. Significant differences were found in the three domains of wellbeing: mental, social and emotional. The educated women were more social, less emotional and more mentally strong compared to uneducated women. In India, limited studies have been conducted to determine the quality of antenatal care. No studies compared the effects of the quality of ANC on mental well-being. This study fills a significant gap in the literature by evaluating the effects of antenatal care quality on mental well-being among women living in low-income housing in Delhi, NCR.

\section{Material and Methods}

The data for this cross-sectional study were collected from women living in low-income housing in Delhi, NCR from April to May 2016. Survey data were collected from 80 pregnant and 75 newly delivered women using a convenience sampling method. Women living in low-income housing of Delhi, Faridabad, Ghaziabad, Noida and Gurugram participated in a 30-minute, one-on-one interview after providing a written consent. The data was collected by the primary researcher and a three-member data collection team. The team was trained for 2 days/2 hours each before the data collection was initiated. Two different valid and reliable measures were adapted to create survey questions: 1. Quality of Prenatal Care Questionnaire [11] and 2. Warwick Edenberg Mental Well-Being Scale (WEMWBS) [12]. The Quality of Prenatal Care Questionnaire factors are: information sharing, anticipatory guidance provided by the health care provider, time spent during the ANC visit, approachability and availability of the provider, and support/respect by provider [10]. The WEMWBS instrument was developed to measure mental well-being in the general population. Mental well-being refers to positive state of thinking, behaving and feeling. The two aspects of mental wellbeing include: states of happiness and life satisfaction; as well as good relationships with others, self-realization/acceptance and psychological functioning [11].

Survey data were entered in Excel and converted to SPSS 24. Thereafter, frequencies were generated to identify missing values and outliers. Other descriptive statistics such as mean, median, and standard deviation were generated to get a description of the variables. Subsequently, chi-square analysis was conducted to study the effect of ANC on well-being among women living in low-income housing. The significant variables in the chi-square analysis were entered in the logistic regression model to control for confounders. 


\section{Journal of Gynecology and Women's Health}

\section{Result}

The analysis of the socio-demographic variables indicated that $52 \%$ of the women were new mothers, and $48 \%$ were pregnant. The majority (56\%) were between the ages of 24-29 years old, illiterate $(55 \%)$, and unskilled workers (97\%). The family income of the $80 \%$ of the participants was $<10,000$ INR. A majority (67\%) accessed ANC in a hospital and experienced medical problems during pregnancy. A majority (36\%) of new mothers accessed ANC in the $1^{\text {st }}$ trimester, followed by $31 \%$ in the $2^{\text {nd }}$ trimester and $33 \%$ in the $3^{\text {rd }}$ trimester. Sixty-eight percent delivered at a hospital and $32 \%$ at home. The deliveries were primarily assisted by a doctor (46\%), followed by nurse (21\%), dai or a home member $(27 \%)$ and an untrained provider (6\%). Sixty percent of the infants were born in week 38 or earlier. The quality of Antenatal Care (ANC) index was calculated by combining factors related to quality of ANC. Fifty-one percent of the women in this study reported that the quality of ANC was low. The Warwick Edenberg Well-Being Scale (WEMWBS) was used to calculate the mental well-being of pregnant women and new mothers. A greater number $(51 \%)$ of women in this study reported experiencing low mental well-being (see Tables 1\&2).

Table 1: Socio-Demographics Variables of the Participants (Pregnant Women: $\mathrm{n}=75$; Newly Delivered Women, $\mathrm{n}=80$ ).

\begin{tabular}{|c|c|c|}
\hline Description & $\mathbf{N}$ & Percent \\
\hline \multicolumn{3}{|l|}{ Pregnancy Status } \\
\hline Pregnant women & 75 & 48 \\
\hline \multirow[t]{2}{*}{ New Mothers } & 80 & 52 \\
\hline & 155 & 100 \\
\hline \multicolumn{3}{|l|}{ Age } \\
\hline $18-23$ & 42 & 27 \\
\hline $24-29$ & 87 & 56 \\
\hline \multirow[t]{2}{*}{$>30$} & 26 & 17 \\
\hline & 155 & 100 \\
\hline \multicolumn{3}{|l|}{ Education of Women } \\
\hline Illiterate & 85 & 55 \\
\hline Primary & 13 & 8 \\
\hline \multirow[t]{2}{*}{ Above Primary } & 57 & 37 \\
\hline & 155 & 100 \\
\hline \multicolumn{3}{|l|}{ Occupation of Women } \\
\hline Skilled worker & 5 & 3 \\
\hline \multirow[t]{2}{*}{ Unskilled worker } & 150 & 97 \\
\hline & 155 & 100 \\
\hline \multicolumn{3}{|l|}{ Family Income (INR) } \\
\hline Below 10,000 & 124 & 80 \\
\hline \multirow[t]{2}{*}{ Above 10,000} & 31 & 20 \\
\hline & 155 & 100 \\
\hline
\end{tabular}

\begin{tabular}{|c|c|c|}
\hline Site of Antenatal Care & & \\
\hline Hospital & 103 & 67 \\
\hline Clinic & 52 & 33 \\
\hline Medical Problem & 155 & 100 \\
\hline Yes & 104 & \\
\hline No & 51 & 67 \\
\hline & 155 & 33 \\
\hline Quality of Antenatal Care & & 100 \\
\hline Low & 79 & 51 \\
\hline High & 76 & 49 \\
\hline & 155 & 100 \\
\hline Mental Well-Being & & \\
\hline Low & 79 & 51 \\
\hline High & 76 & 49 \\
\hline & 155 & 100 \\
\hline
\end{tabular}

Table 2: Service Utilization Among Newly Delivered Women $(n=80)$.

\begin{tabular}{|c|c|c|}
\hline Description & $\mathbf{N}$ & Percent \\
\hline \multicolumn{3}{|l|}{ Site of Delivery } \\
\hline Hospital & 54 & 68 \\
\hline \multirow[t]{2}{*}{ Home } & 26 & 32 \\
\hline & 80 & 100 \\
\hline \multicolumn{3}{|l|}{ Mode of Delivery } \\
\hline Vaginal & 79 & 99 \\
\hline \multirow[t]{2}{*}{ Cesarean } & 1 & 1 \\
\hline & 80 & 100 \\
\hline \multicolumn{3}{|l|}{ Delivery Provider } \\
\hline Doctor & 37 & 46 \\
\hline Nurse & 17 & 21 \\
\hline Dai/Home Member & 21 & 27 \\
\hline \multirow[t]{2}{*}{ Untrained Provider } & 5 & 6 \\
\hline & 80 & 100 \\
\hline \multicolumn{3}{|c|}{ Infants Gestational Age at Delivery } \\
\hline \multicolumn{3}{|l|}{$<=38$ weeks } \\
\hline \multirow[t]{3}{*}{$39+$} & 48 & 60 \\
\hline & 32 & 40 \\
\hline & 80 & 100 \\
\hline \multicolumn{3}{|l|}{ Time of ANC } \\
\hline First trimester & 29 & 36 \\
\hline Second trimester & 25 & 31 \\
\hline \multirow[t]{2}{*}{ Third trimester } & 26 & 33 \\
\hline & 80 & 100 \\
\hline
\end{tabular}


Table 3: Bivariate Analysis of the Effect of Mother's Education, Family Income, Medical Problem, Quality of ANC and Time of ANC Visit on Mental Well-Being on Pregnant and Newly Delivered Women.

\begin{tabular}{|c|c|c|c|c|c|c|c|}
\hline \multirow{2}{*}{ Variable } & \multicolumn{2}{|c|}{ Low Mental Well-Being } & \multicolumn{2}{|c|}{ High Mental Well-Being } & \multirow{2}{*}{ Chi-Square } & \multirow{2}{*}{ df } & \multirow{2}{*}{ p-value } \\
\hline & $\mathbf{n}$ & $\%$ & $\mathbf{n}$ & $\%$ & & & \\
\hline \multicolumn{8}{|l|}{ Education } \\
\hline Illiterate & 44 & 51.8 & 41 & 48.2 & 0.898 & 2 & 0.638 \\
\hline Primary & 8 & 61.5 & 5 & 38.5 & & & \\
\hline Above Primary & 27 & 47.4 & 30 & 52.6 & & & \\
\hline \multicolumn{8}{|l|}{ Family Income (INR) } \\
\hline$<10,000$ & 60 & 48.4 & 64 & 51.6 & 1.652 & 1 & 0.199 \\
\hline$>10,000$ & 19 & 61.3 & 12 & 38.7 & & & \\
\hline \multicolumn{8}{|l|}{ Medical Problem } \\
\hline Yes & 49 & 47.1 & 55 & 52.9 & 1.877 & 1 & 0.171 \\
\hline No & 30 & 58.8 & 21 & 41.2 & & & \\
\hline \multicolumn{8}{|l|}{ Quality of ANC } \\
\hline Low & 47 & 59.5 & 32 & 42.1 & 4.687 & 1 & $.030^{*}$ \\
\hline High & 32 & 40.5 & 44 & 57.9 & & & \\
\hline \multicolumn{8}{|l|}{ Time of ANC } \\
\hline First Trimester & 10 & 34.5 & 19 & 65.5 & 16.095 & 2 & $.001^{*}$ \\
\hline Second Trimester & 10 & 40 & 15 & 60 & & & \\
\hline Third Trimester & 22 & 84.6 & 4 & 15.4 & & & \\
\hline
\end{tabular}

Bivariate analysis indicated significant associations between quality and time of ANC services and mental well-being of women. Fifty-nine percent of women who received low quality of ANC reported low mental well-being compared to $40.5 \%$ of women who received high quality of ANC. Whereas, 57.9\% of those who received high quality of ANC reported high mental well-being as compared to $42.1 \%$ who received low quality ANC. The association between quality of ANC and mental well-being was significant (chi-square=4.687, $\mathrm{df}=1, \mathrm{p}=.030$ ). In reference to time of $\mathrm{ANC}$, those who accessed ANC in the $3^{\text {rd }}$ trimester $(84.6 \%)$ reported low mental well-being followed by those who accessed in $2^{\text {nd }}(40 \%)$ and $1^{\text {st }}$ trimesters (34.5\%). Similarly, $65.5 \%$ of those who accessed ANC in the $1^{\text {st }}$ trimester reported high mental well-being followed by those who accessed in $2^{\text {nd }}(60 \%)$ and $3^{\text {rd }}$ trimester $(15.4 \%)$. The association between time of ANC and mental well-being was significant (chi-square $=16.095, \mathrm{df}=2, \mathrm{p}$-value=.001). Education (chi-square=.898, df=2, p-value=.638), family income (chisquare $=1.652, \mathrm{df}=1, \mathrm{p}$-value $=.199$ ) and medical problems during pregnancy (chi-square=1.877, $\mathrm{df}=1, \mathrm{p}$-value=.171) were not significantly associated with mental well-being. The significant variables in the chi-square analysis were entered in the logistic model to control for the confounders (see Table 3).
Table 4: Logistic Regression Model: Effect of Quality and Time of ANC on Mental Well-Being of Women.

\begin{tabular}{|c|c|c|c|}
\hline Variable & B & Odds-Ratio & p-value \\
\hline Quality of ANC & 1.055 & 2.872 & $.004^{*}$ \\
\hline ANC in First Trimester & 1.396 & 4.041 & $.004^{*}$ \\
\hline ref category & & & \\
\hline Third Trimester & & & \\
\hline ANC in Second Trimester & 0.944 & 2.57 & $.049^{*}$ \\
\hline ref. category & & & \\
\hline Third Trimester & & & \\
\hline
\end{tabular}

The quality and time of ANC were associated with mental wellbeing in the logistic regression model. Women who received high quality of ANC were nearly 3 times more likely to report better mental well-being $(B=1.055$, odds ratio $=2.872$, p-value $=.004)$. Those who accessed ANC in the $1^{\text {st }}$ trimester compared to $3^{\text {rd }}$ trimester were 4 times more likely to report better mental wellbeing $(B=1.396$, odds ratio=4.041, $p$-value=.004). Similarly, those who accessed ANC in $2^{\text {nd }}$ trimester were nearly 3 times more likely to report better mental well-being compared to those in $3^{\text {rd }}$ trimester ( $\mathrm{B}=.944$, odds-ratio=2.570, $\mathrm{p}$-value=.049) (see Table 4). 


\section{Discussion}

In this study, quality and time of ANC were important factors in determining the mental well-being of women. Those who reported using ANC in the $1^{\text {st }}$ trimester reported high mental well-being score $(65.5 \%)$; followed by $60 \%$ who accessed in $2^{\text {nd }}$ trimester; and $15.4 \%$ who accessed in the $3^{\text {rd }}$ trimester (chisquare=16.095, p=.001). Even after controlling for confounders in the logistic regression model, time of ANC remained significantly associated with mental well-being. Women who accessed ANC in the $1^{\text {st }}$ trimester were 4 times more likely to report better mental well-being compared to those in the $3^{\text {rd }}$ trimester $(B=1.396$, oddsratio $=4.041$, $p$-value $=.004)$. Followed by women who used ANC in the $2^{\text {nd }}$ trimester, they were two times more likely to report better mental well-being compared to those in the $3^{\text {rd }}$ trimester $(B=.944$, odds-ratio $=2.570, p$-value $=.049)$. Early access to ANC can be critical in ensuring a safe and healthy pregnancy. In this study, women who accessed ANC early reported better mental well-being scores. In fact, $84.6 \%$ of women who utilized ANC in the $3^{\text {rd }}$ trimester reported low mental well-being. Kumar et al. analyzed the NFHS-4 survey to determine that $28.4 \%$ of women used ANC in the $1^{\text {st }}$ trimester, $63.3 \%$ in the $2^{\text {nd }}$ trimester and $8.04 \%$ in the third trimester [7]. Whereas, in this study $36 \%$ utilized ANC in the $1^{\text {st }}$ trimester, $31 \%$ in $2^{\text {nd }}$ trimester and $33 \%$ in the $3^{\text {rd }}$ trimester. Fifty-eight percent of women who experienced high quality care reported high mental well-being. On the other hand, $60 \%$ of those experienced low-quality ANC reported low mental well-being (chi-square $=4.687$, $\mathrm{p}$-value=.030). Those who received high quality of ANC were nearly three times more likely to report better mental well-being in the logistic model $(B=1.055$, odds=2.872, p-value=.004). Optimal ANC quality can be effective in protecting mother and child health. Satisfaction with the quality of ANC positively influenced mental well-being in women, in this study. Fifty-nine percent reported experiencing poor quality of information sharing by their provider. Five-one percent received poor anticipatory guidance, and $51 \%$ had insufficient time with their provider during ANC visits. Fifty-six percent felt that their provider was unapproachable, and 51\% reported poor availability of their provider. Most importantly, 87\% experienced low support and respect. In a prospective cohort study conducted in a tertiary medical hospital in Southern India, a majority of the antenatal care quality domains scored above $90 \%$. In reference to the interpersonal interaction domain, for example, $95.5 \%$ of the women received an explanation before examination, and $100 \%$ were greeted politely. In the physical examination domain, $99.5 \%$ had their blood pressure evaluated. In the health education domain, 98\% received advice on iron rich foods [13].

In this study, socio-economic variables, such as income and education were not associated with well-being in this study. A majority of women who had above primary education reported high mental well-being (52.6\%) in the chi-square analysis. Whereas, a majority of those with primary education reported low mental well-being (61.5\%). It is important to note that $55 \%$ of women in this study were illiterate, and $80 \%$ had a family income below 10,000 INR. A study done on housewives with primary $\left(0-8^{\text {th }}\right.$ grade $)$ and post graduate education in Sir Syed colony of Aligrah found that overall well-being of the educated women was higher than the uneducated women. Significant differences were found between the 3 domains of well-being: mental, social and emotional well-being. Educated women were mentally stronger, less emotional and more sociable [10]. In this study, the majority $(67 \%)$ of the women experienced medical problems during pregnancy, but they were not associated with the mental well-being (chi-square=1.877, p=.171). Sixty-eight percent of the deliveries were in a hospital and $32 \%$ at home. However, the percent of hospital deliveries was lower than the national average of 79\% in years 2015-2016 (NFHS-4) [1]. Forty-six percent of the deliveries were assisted by a doctor, $21 \%$ by a nurse, $27 \%$ by a dai or home member and $6 \%$ by an untrained provider. In a study conducted in the slums of Mohali, Punjab it was found that $49.1 \%$ of the women delivered at home. Sixty-six deliveries were conducted by a trained SBA, of which only 3 deliveries were conducted by a government SBA, whereas $77 \%$ were conducted by an unknown private SBA. Nineteen percent of the deliveries were unsafe as they were conducted without any SBA assistance at home. ${ }^{[14]}$ Data from NFHS-4 indicated that skilled birth attendance decreased from $96 \%$ to $64 \%$ among women in the lowest wealth quintile [1].

Marginalized women living in low-income housing in Delhi have limited access to quality ANC services which adversely effects their mental well-being. In addition, those who access ANC in the $1^{\text {st }}$ and the $2^{\text {nd }}$ trimester report better well-being that those in the $3^{\text {rd }}$ trimester. The government, civil society organizations and private institutions need to increase access to quality antenatal services among women who live in low-income housing in Delhi, NCR. Policies and programs focused on social inclusion of marginalized women are essential for improving health and mental well-being of women. This can also be achieved by strengthening the existing government funded programs such as Janani Suraksha Yogna (JSY) [15] and Accredited Social Health Activist (ASHA) [16] program, JSY is an ambitious cash transfer program aimed at promoting institutional delivery. ASHA workers provide critical support in improvement of ANC programs. These programs can be further leveraged to improve quality of ANC and overall well-being of poor-urban women.

\section{Acknowledgement}

The authors would like to thank the Research Librarian, Marilyn Reside and John Perra for editing the manuscript.

\section{References}

1. National Institute of Population Science (2010) National Family Health Survey (NFHS-4).

2. Agarwal P, Singh MM, Garg S (2007) Maternal health-care utilization among women in an urban slum in Delhi. Indian J of Community Med 32(3): 203-205. 
3. Gupta I, Guin P (2015) Health status and access to health services in urban slums. Health 7: 245-255.

4. Sanneving L, Trygg N, Saxena D, Mavalankar D, Thomsen S, et al. (2013) Inequity in India: the case of maternal and reproductive health. Global health action 6: 19145 .

5. Hazarika I (2010) Women's reproductive health in slum populations in India: evidence from NFHS-3. J Urban Health 87(2): 264-277.

6. Jat TR, Ng N, Sebastian MS (2011) Factors affecting the use of maternal health services in Madhya Pradesh State of India: a multilevel analysis. Int J Equity Health 10: 59.

7. Kumar G, Choudhary TS, Srivastava A, Upadhyay Ra, Taneja S, et al (2019) Utilisation, equity and determinants of full antenatal care in India: analysis from the National Family Health Survey 4. BMC Pregnancy Childbirth 19(1): 327.

8. Afulani PA, Buback L, Essandoh F, Kinyua J, Kimburi L, et al. (2019) Quality of antenatal care and associated factors in a rural county in Kenya: an assessment of serviced provision and experience dimensions. BMC Health Services Research 19: 684.

9. Joshi C, Torvaldsen S, Hodgson R, Hayen A (2014) Factors associated with the use and quality of antenatal care in Nepal: a population-based study using the demographic and health survey data. BMC Pregnancy Childbirth 14: 94.
10. Javed S, Javed S, Khan A, Akhtar-Danesh A, Tough S, et al. (2016) Effects of education on quality of life and well being. The International Journal of Indian Psychology 3(3): 116.

11. Heaman MI, Sword WA, Akhtar-Danesh N (2014) Quality of prenatal care questionnaire: instrument development and testing. BMC Pregnancy Childbirth 14: 188.

12. Warwick Medical School (2018) The Warwick-Edinburgh Mental Wellbeing Scales - WEMWBS.

13. Pricilla RA, David KV, Siva R, Vimala TJ, Rahman SP, et al. (2017) Quality of antenatal care provided by nurse midwives in an urban health centre with regard to low-risk antenatal mothers. Indian J Community Med 42(1): 37-42.

14. Phawa P, Sood A (2013) Existing practices and barriers to access of MCH services - a case study of residential urban slums of district Mohali, Punjab, India. Global Journal of Medicine and Public Health, p. 2.

15. UNFPA (2009) Concurrent Assessment of Janani Suraksha Yogana (JSY) scheme in selected states of India, 2008.

16. Fathima FN, Raju M, Varadharajan KS, Krishnamurthy A, Ananthkumar SR, et al. (2015) Assessment of 'accredited social health activists'-a national community health volunteer scheme in Karnataka State, India. J Health Popul Nutr 33(1): 137-145.

\section{Your next submission with Juniper Publishers will reach you the below assets}

- Quality Editorial service

- Swift Peer Review

- Reprints availability

- E-prints Service

- Manuscript Podcast for convenient understanding

- Global attainment for your research

- Manuscript accessibility in different formats

( Pdf, E-pub, Full Tsext, Audio)

- Unceasing customer service

Track the below URL for one-step submission https://juniperpublishers.com/online-submission.php 